\title{
Dorsal Bridge Plating versus External Fixation for Distal Radius Fractures
}

\author{
William L. Wang, MD ${ }^{1}$ Asif M. Ilyas, MD ${ }^{1}$ \\ ${ }^{1}$ Department of Orthopaedic Surgery, Thomas Jefferson University \\ and the Rothman Institute, Philadelphia, Pennsylvania \\ Address for correspondence Asif M. Ilyas, MD, FACS, Department of \\ Orthopaedic Surgery, Thomas Jefferson University and the Rothman \\ Institute, 925 Chestnut Street, Philadelphia, PA 19107 \\ J Wrist Surg 2020;9:177-184 \\ (e-mail: asif.ilyas@rothmaninstitute.com).
}

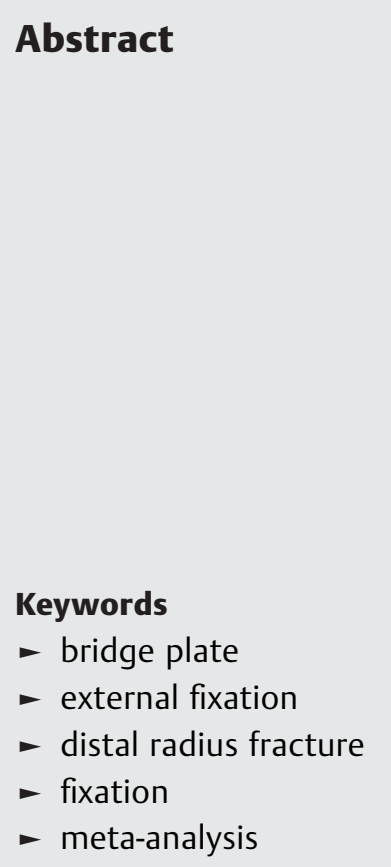

Background External fixation and dorsal bridge plating are wrist spanning fixation options for distal radius fractures; however, their comparative effectiveness is not well understood. A meta-analysis was conducted to compare the clinical outcomes between these two techniques.

Materials and Methods A PubMed database query of all distal radius fracture cases managed with spanning external fixation or dorsal bridge plating was performed. A total of 28 articles met inclusion criteria, yielding 895 patients for data extraction and comparative analysis.

Results Dorsal bridge plating demonstrated lower rates of infection ( 2 vs. $10 \%, p=$ 0.05 ) and complex regional pain syndrome ( 1 vs. $4 \%, p=0.04$ ) but higher rates of hardware failure ( 4 vs. $1 \%, p=0.026$ ). Bridge plating also demonstrated higher rates of excellent/good ratings under the Gartland and Werley outcome score (91 vs. 83\%, $p=$ 0.016). There was no significant difference in DASH (Disability of the Arm, Shoulder, and Wrist) scores, radiographic parameters, or unplanned reoperations between the two spanning fixation options.

Conclusion Bridge plating and external fixation both appear to be comparable for spanning fixation constructs for distal radius fractures, but with bridge plating having a potentially lower complication profile.
Distal radius fractures are the most common upper extremity fracture, representing up to $16 \%$ of all fractures seen in the emergency department. ${ }^{1-3}$ The surgical indications for distal radius fractures generally include displaced or unstable fracture patterns. Several fracture fixation constructs are available, with external fixation ("ExFix") being a common and proven technique. ${ }^{4}$ The technique involves a closed reduction, or limited open reduction, with ligamentotaxis and application of an ExFix frame to the radius proximally and the index metacarpal distally thereby spanning the fracture and wrist joint ( - Fig. 1 A and B). More recently, dorsal bridge plating has been introduced as an alternative to ExFix. ${ }^{5,6}$

The dorsal bridge plate ("bridge plate") technique was originally introduced in 1998, with the goal to manage frac- tures of the distal radius with extensive articular comminution, and/or for fractures with metadiaphyseal extension. ${ }^{5}$ The technique involves a closed or limited open fracture reduction, and insertion of a long-straight dorsal bridge plate under the second or fourth dorsal compartments of the wrist with fixation to the dorsal radial shaft proximally and the index or middle metacarpal shaft distally with multiple screws ( - Fig. 2A and B). Conceptually, it was considered as an "internal ExFix" as it similarly spans the fracture and wrist joint, but provides the added advantage of all internal fixation and theoretically avoids complications associated with pins and prominent hardware. Over the years, authors have refined the technique and increased the indication to manage osteoporotic fractures of the distal radius, fractures with extensive articular, received

December 15, 2018

accepted

June 25, 2019

published online

August 8, 2019
Copyright (c) 2020 by Thieme Medical Publishers, Inc., 333 Seventh Avenue, New York, NY 10001, USA. Tel: +1(212) 760-0888.
DOI https://doi.org/ 10.1055/s-0039-1694063. ISSN 2163-3916. 

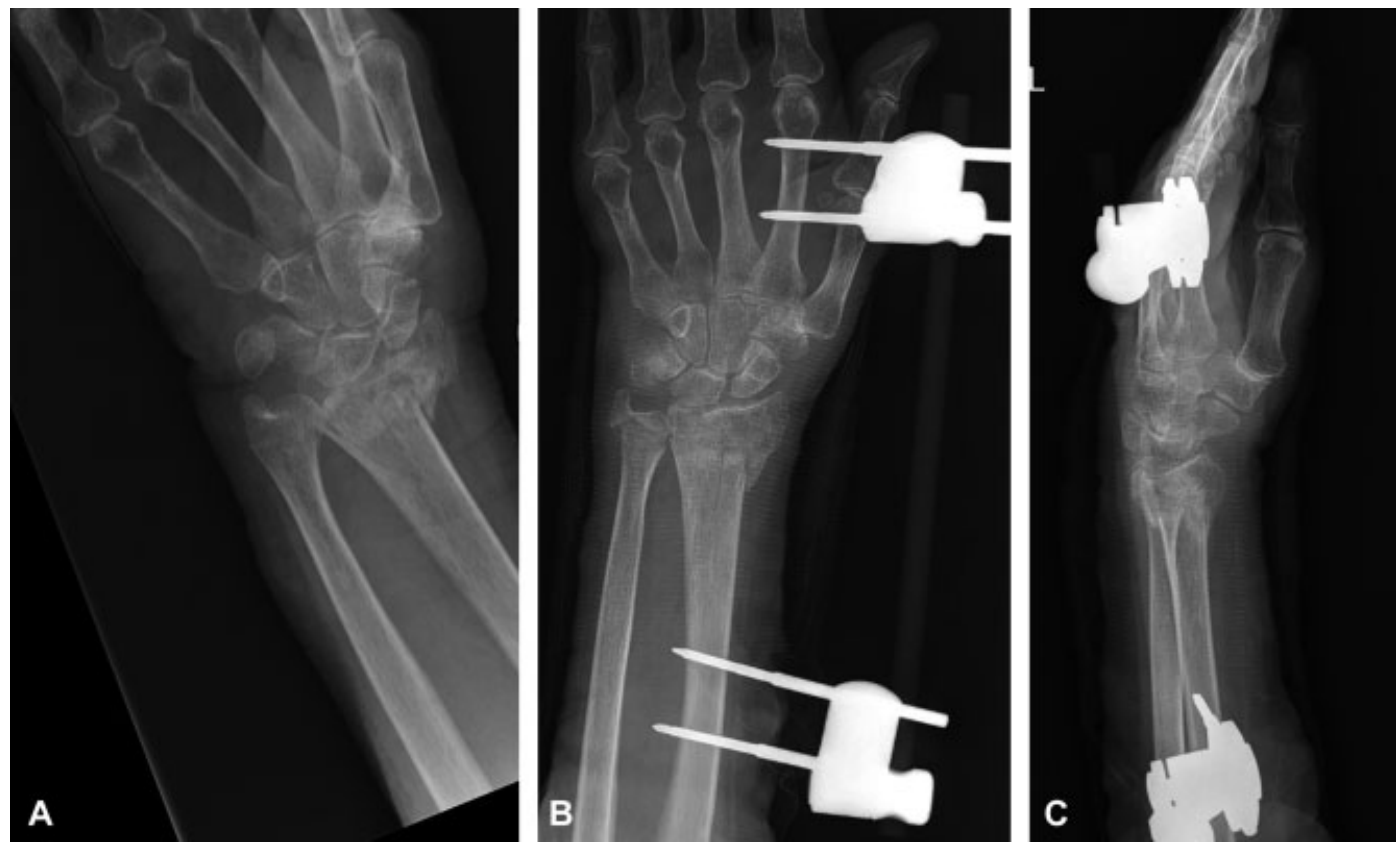

Fig. 1 (A-C) Distal radius fracture treated with a wrist-spanning dorsal bridge plate.

and/or metadiaphyseal comminution, or in cases of fracture with radiocarpal instability. ${ }^{6-9}$ More recently, with the advent of anatomically designed low-profile bridge plates with locking screw technology, their indications have expanded to include its use in polytrauma patients and/or patients who need to ambulate with assistive devices through the injured wrist. ${ }^{10}$

There are advantages and disadvantages with an ExFix and bridge plate in the management of distal radius fractures. One of the main advantages of bridge plate is the avoidance of pin track infections or the inconvenience of prominent hardware.
In addition, because it is placed below the skin, a bridge plate can be left in the position for a longer period of time. Alternatively, the main disadvantage of a bridge plate is the need for a secondary operation for plate removal. ${ }^{11}$

Despite these purported advantages, little is understood about the functional comparative difference between a bridge plate versus an ExFix technique. Therefore, to better understand the comparative advantages and disadvantages of these two fracture-fixation techniques for distal radius fractures, a meta-analysis was undertaken.
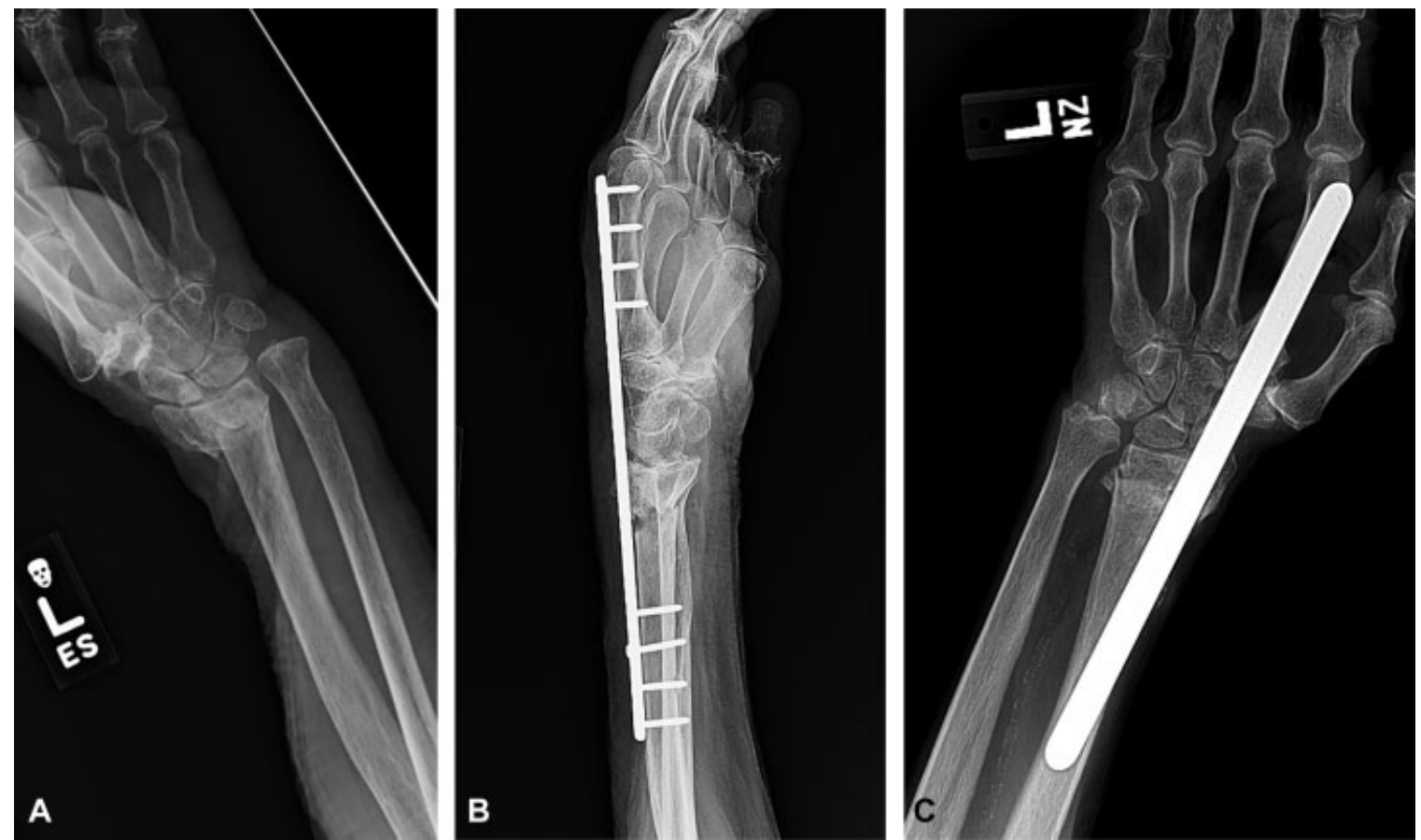

Fig. 2 (A-C) Distal radius fracture treated with external fixation. 


\section{Materials and Methods}

Articles from January 1, 2005 to September 9, 2017 were queried on the PubMed database. This "modern" time period was used to minimize implant technology related variability. Search terms for the ExFix and bridge plate studies included "(external fixator) and distal and radius" and "(bridge or bridging or spanning) and (plate or plating) and distal and radius," respectively. All articles were reviewed and selected based on inclusion and exclusion criteria. Studies meeting inclusion criteria were case series, retrospective studies, observational cohort studies, and randomized controlled trials with available functional outcome data of wrist spanning ExFix and bridge plate fixation. Exclusion criteria included use of dynamic ExFix, nonspanning wrist ExFix, and ExFix or bridge plating augmented with any additional internal fixation.

Each article was reviewed and the following data were extracted: demographic data, AO (Arbeitsgemeinschaft für Osteosynthesefragen) fracture classification, functional outcome measures, postoperative radiographic parameters, and complications. For functional outcomes, we collected functional outcome data from the Disabilities of the Arm, Shoulder, and Hand (DASH) and the Gartland and Werly questionnaires. Radiographic parameters included radial height, radial inclination, volar tilt, and ulnar variance.
Data from all studies were combined and compared across the two treatment teams using generalized linear models using SPSS, and descriptive statistics were performed.

\section{Results}

The literature initial search yielded 489 ExFix articles and 22 bridge plate articles for review. After applying the inclusion and exclusion criteria (-Figs. 3 and 4), 22 and six articles were remained for inclusion and exclusion, respectively (-Table 1). Overall, 172 patients were treated with bridge plating and 723 patients treated with ExFix.

The mean age for the bridge plate and ExFix groups were 56.9 and 53.9 years, respectively. The bridge plating group consisted of a higher proportion of male patients ( $55 \mathrm{vs.} 35.8 \%$, $p=0.011$ ). Mean follow-up time was 17.3 and 18.9 months, respectively. Time to hardware removal for the bridge plate group was higher than the ExFix group (17.6 vs. 6.2 weeks, $p<0.001)$. The bridge plate group also consisted of more dominant extremities (70.6 vs. $50.4 \%, p=0.03$ ). While there were no significant differences in proportion of $\mathrm{AO}$ fracture type A ( 14 vs. $24.5 \%, p=0.31$ ) and C ( 80.1 vs. $76.9 \%$, $p=0.73$ ), the bridge plate group had a higher proportion of AO fracture type B ( 5.8 vs. $0.3 \%, p=0.013$ ). See - Table 2 for a comparison of additional variables and demographic factors.
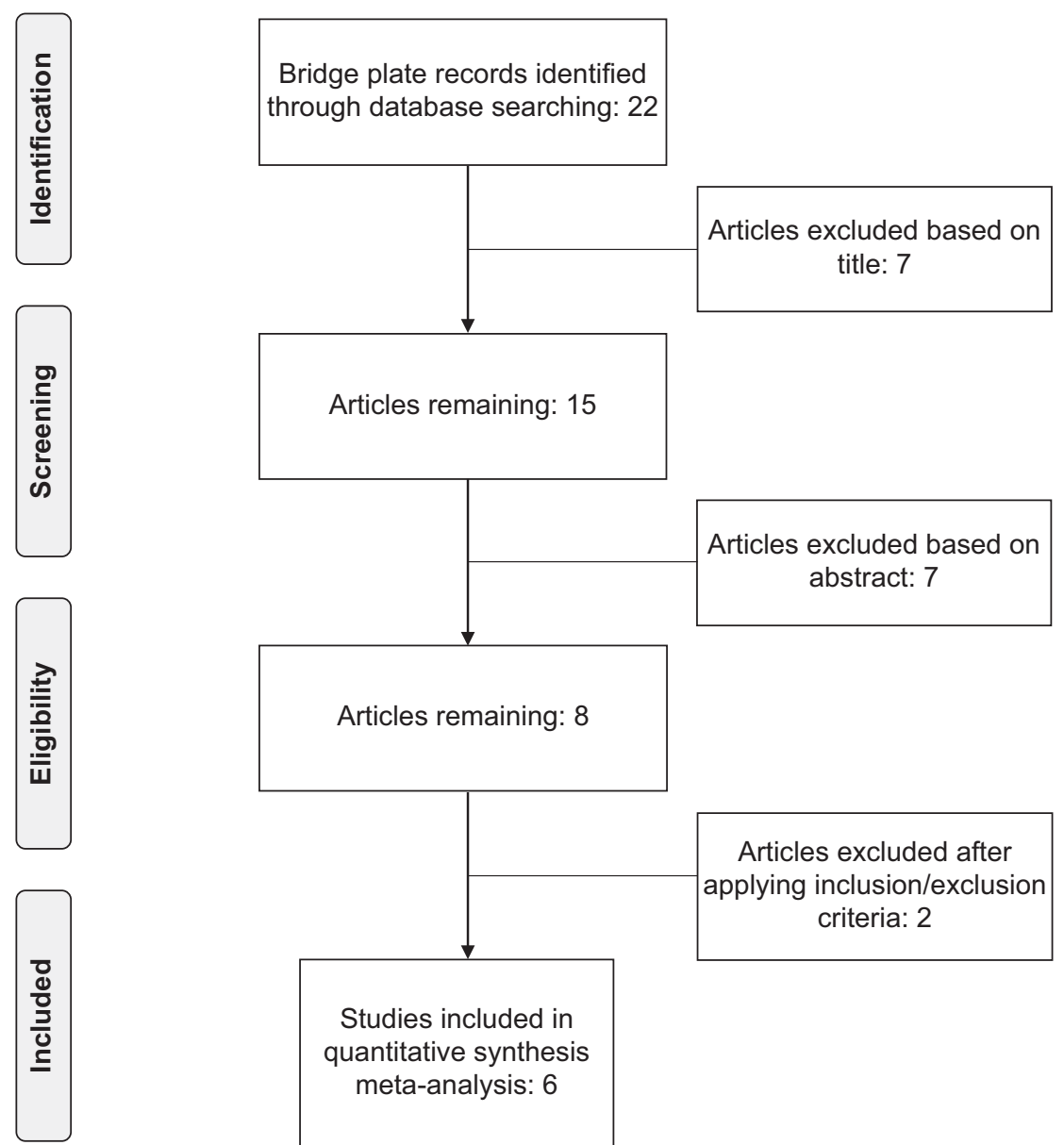

Studies included in quantitative synthesis meta-analysis: 6

Fig. 3 Flow diagram of literature search for external fixation articles. 


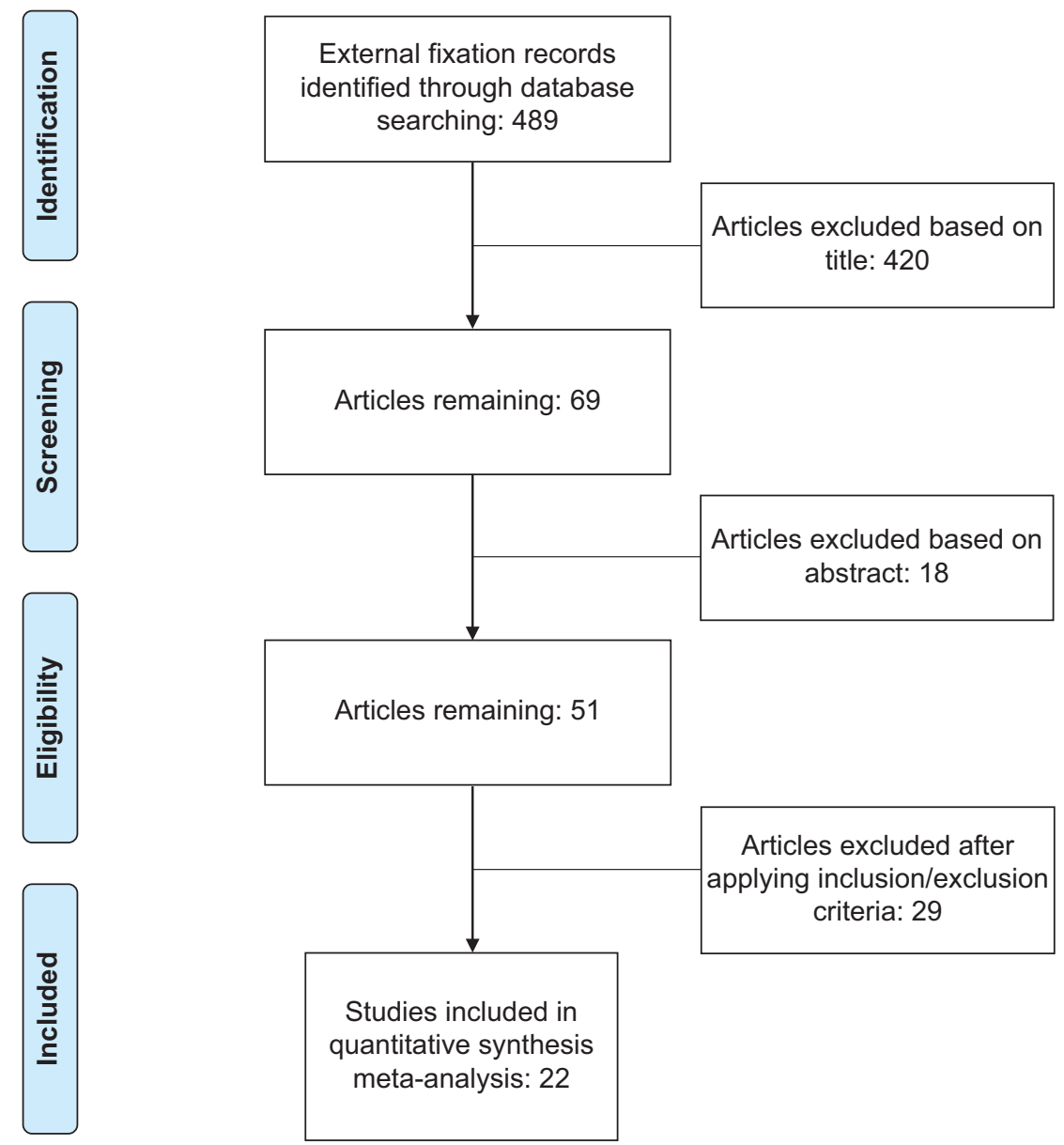

Fig. 4 Flow diagram of literature search for bridge plate articles.

The bridge plating group demonstrated higher rates of hardware failure compared with ExFix ( 4 vs. $1 \%, p=0.026$ ). The external fixator group demonstrated higher rates of infection ( 10 vs. $2 \%, p=0.05$ ) and complex-regional pain syndrome ( 4 vs. $1 \%, p=0.04$ ). Bridge plating demonstrated higher rates of excellent/good ratings under the Gartland and Werley outcome score compared with ExFix (91 vs. 83\%, $p=0.016)$. Although ExFix demonstrated higher rates of nerve palsy and other nerve complications, this was not statistically significant ( 3 vs. $1 \%, p=0.063$ ). There were no statistically significant differences in DASH score, radiographic parameters (radial height, radial inclination, volar tilt, and ulnar variance). There were no differences in the rate of unplanned reoperations. See $\mathbf{-}$ Table 3 for a complete list of comparative outcomes between the bridge plating and ExFix groups.

\section{Discussion}

ExFix is a well proven technique in the management of distal radius fractures. Bridge plating is a newer technique that builds on the concept of spanning and fixing the reduced and distracted distal radius fracture but provides some additional potential benefits including less-prominent hardware complications, the ability to keep the hard- ware in position longer, and the ability to allow for immediate weight bearing across the fractured distal radius. Both techniques are useful to have in an upper extremity surgeon's armamentarium.

Our meta-analysis found several interesting findings. Bridge plating demonstrated lower rates of infection and complex regional pain syndrome, although had higher rates of hardware failure when compared with ExFix. The higher infection rate is not unexpected, given that pin tract infections are one of the known disadvantages to ExFix and a primary limitation to time to hardware removal. ${ }^{12-17}$ Despite the differences in complication rates in infection, hardware failure, and complex regional pain syndrome, there was no difference in unplanned reoperations between the two groups. The majority of pin tract infections can be successfully treated with antibiotics; ultimately, only two patients from the external fixator group required a secondary irrigation and debridement operation for infection. ${ }^{15}$ Hardware failure in the bridge plating group often occurred after 8 weeks, which would be anticipated to have occurred after the fracture had healed. $6,10,18$ Since patients treated with Bridge Plate will undergo a planned secondary procedure for hardware removal, hardware failure in this group has less clinical significance if it occurs after fracture union. Complex regional pain syndrome occurred at a higher rate in the ExFix group and was commonly treated with 
Table 1 Demographics for data evaluating outcomes after bridge plating and external fixation

\begin{tabular}{|c|c|c|c|c|c|c|c|c|c|}
\hline \multicolumn{10}{|c|}{ Demographics for data evaluating outcomes after bridge plating } \\
\hline Article authors & $\begin{array}{l}\text { Year of } \\
\text { publication }\end{array}$ & Design & Patients & $\begin{array}{l}\text { Mean } \\
\text { age (y) }\end{array}$ & $\begin{array}{l}\text { AO } \\
\text { type A } \\
n(\%)\end{array}$ & $\begin{array}{l}\text { AO } \\
\text { type B } \\
n(\%)\end{array}$ & $\begin{array}{l}\text { AO } \\
\text { type C } \\
n(\%)\end{array}$ & $\begin{array}{l}\text { Follow-up } \\
\text { (mo) }\end{array}$ & $\begin{array}{l}\text { Hardware } \\
\text { removal } \\
\text { (wk) }\end{array}$ \\
\hline $\begin{array}{l}\text { Tinsley and } \\
\text { llyas }{ }^{10}\end{array}$ & $\begin{array}{l}2018 \\
\text { (e-pub 2017) }\end{array}$ & Retrospective & 11 & 72 & $4(36)$ & $0(0)$ & $7(64 \%)$ & - & - \\
\hline Lauder et al & 2015 & Retrospective & 18 & 61 & $0(0)$ & $0(0)$ & $18(100)$ & 34.8 & 12 \\
\hline Dodds et $\mathrm{al}^{18}$ & 2013 & Retrospective & 25 & 54.6 & $0(0)$ & $7(28)$ & $18(72)$ & 6.6 & 26.5 \\
\hline Richard et $\mathrm{al}^{8}$ & 2012 & Retrospective & 33 & 70 & $0(0)$ & $0(0)$ & $33(100)$ & 10.8 & 17 \\
\hline Hanel et $\mathrm{al}^{6}$ & 2006 & Retrospective & 62 & 47.8 & $18(29)$ & $3(5)$ & $41(66)$ & & \\
\hline Ruch et $\mathrm{al}^{9}$ & 2005 & Retrospective & 22 & 54.6 & $2(9)$ & $0(0)$ & $20(91)$ & 24.8 & 17.7 \\
\hline Total & & & 171 & & & & & & \\
\hline \multicolumn{10}{|c|}{ Demographics for data evaluating outcomes after external fixation } \\
\hline Roh et al & 2015 & Prospective & 38 & 55.3 & $0(0)$ & $0(0)$ & $38(100)$ & 12 & 5.3 \\
\hline Shukla et al & 2014 & Prospective & 62 & 39 & - & - & - & 12 & 8 \\
\hline Kumbaraci et $\mathrm{al}^{12}$ & 2014 & Retrospective & 35 & 52.6 & $0(0)$ & $0(0)$ & $35(100)$ & 24.5 & - \\
\hline Williksen et $\mathrm{al}^{13}$ & 2013 & Prospective & 59 & 54 & $14(24)$ & $0(0)$ & $45(76)$ & 12 & 6 \\
\hline Jeudy et al & 2012 & Prospective & 39 & 64.6 & $0(0)$ & $0(0)$ & $39(100)$ & 6 & 6 \\
\hline Grewal et al ${ }^{14}$ & 2011 & Prospective & 24 & 53.8 & - & - & - & 12 & 6 \\
\hline Richard et al ${ }^{8}$ & 2011 & Retrospective & 59 & 50 & $0(0)$ & $0(0)$ & $59(100)$ & 12 & - \\
\hline Wilcke et al & 2011 & Prospective & 30 & 56 & $22(73)$ & $0(0)$ & $8(27)$ & 12 & 5 \\
\hline Gereli et al & 2010 & Retrospective & 14 & 35 & $0(0)$ & $0(0)$ & $14(100)$ & 62.7 & 7.8 \\
\hline Hove et al & 2010 & Prospective & 35 & 54 & $19(54)$ & $0(0)$ & $16(46)$ & 12 & 6 \\
\hline Belloti et al & 2010 & Prospective & 49 & 59.2 & - & - & - & 24 & 6 \\
\hline Sato et al & 2010 & Retrospective & 13 & 65.8 & $4(31)$ & $0(0)$ & $9(69)$ & 23 & - \\
\hline Aktekin et al ${ }^{19}$ & 2010 & Retrospective & 22 & 69.8 & $9(41)$ & $0(0)$ & $13(59)$ & 27 & 6 \\
\hline Abramo et al & 2009 & Prospective & 24 & 48 & $4(17)$ & $0(0)$ & $20(83)$ & 12 & - \\
\hline Wei et al & 2009 & Prospective & 22 & 55 & $10(45)$ & $0(0)$ & $12(55)$ & 12 & - \\
\hline $\begin{array}{l}\text { Schmelzer- } \\
\text { Schmied et al }\end{array}$ & 2009 & Retrospective & 15 & - & $0(0)$ & $0(0)$ & $15(100)$ & 72 & 6 \\
\hline Egol et al & 2008 & Prospective & 44 & 49.9 & $16(36)$ & $2(5)$ & 26 (59) & 12 & 6 \\
\hline Leung et $\mathrm{al}^{15}$ & 2008 & Prospective & 49 & - & $0(0)$ & $0(0)$ & $49(100)$ & 24 & - \\
\hline Atroshi et al ${ }^{16}$ & 2006 & Prospective & 19 & 71 & $8(42)$ & $0(0)$ & $11(58)$ & 12 & 6 \\
\hline Kreder et al ${ }^{17}$ & 2006 & Prospective & 44 & 52.4 & $35(80)$ & $0(0)$ & $19(43)$ & 44 & - \\
\hline Wright et al ${ }^{20}$ & 2005 & Retrospective & 11 & 50 & $3(27)$ & $0(0)$ & $8(73)$ & 24 & - \\
\hline Hegeman et al ${ }^{21}$ & 2005 & Retrospective & 16 & 67 & $0(0)$ & $0(0)$ & $16(100)$ & 48 & 6 \\
\hline
\end{tabular}

therapy. ${ }^{12,13,19-21}$ While this difference may influence functional and satisfaction outcomes, it had negligible influence on unplanned reoperation.

Patients treated with Bridge Plate demonstrated higher Gartland and Wearly scores compared with ExFix. The Gartland and Werley scoring system was initially described in $1951 .^{22}$ While it is used widely in the literature, it has not been validated by studies to date. When comparing scores using the validated DASH questionnaire, there were no differences between the two groups. ${ }^{23,24}$ With this in mind, we are not able to conclude that one treatment group had superior clinical outcomes than the other.

\section{Limitations}

There are limitations to this study. We were not able to find any comparative studies in our literature search, evaluating the efficacy and outcomes of bridge plating and ExFix within a single cohort. Furthermore, there are a limited number of bridge plating studies in the literature, consisting mostly of retrospective case series. This limited our ability to generate and compare effect sizes for outcome measures.

Another limitation is lack of randomization which is demonstrated by the differences in baseline patient characteristics between the bridge plating and external fixator 
182 Dorsal Bridge Plating versus External Fixation Wang, Ilyas

Table 2 Comparison of additional variables and demographic factors

\begin{tabular}{|l|l|l|l|}
\hline Demographic data & Bridge plate mean & External fixation mean & $p$-Value \\
\hline Variable & $56.90(47.84-65.96)$ & $53.85(49.84-57.86)$ & 0.532 \\
\hline Age (y) & $88(55.0 \%)$ & $215(35.8 \%)$ & 0.011 \\
\hline Male gender & $17.29(6.71-27.86)$ & $18.85(14.08-23.61)$ & 0.784 \\
\hline Follow-up (mo) & $17.63(14.06-21.21)$ & $6.20(5.61-6.78)$ & $<0.001$ \\
\hline Time to removal of hardware (wk) & $72(70.6)$ & $138(50.4)$ & 0.028 \\
\hline Dominant extremity $n(\%)$ & $24(14.0)$ & $144(24.5)$ & 0.308 \\
\hline AO fracture type A $n(\%)$ & $10(5.8)$ & $2(0.3)$ & 0.013 \\
\hline AO fracture type B $n(\%)$ & $137(80.1)$ & $452(76.9)$ & 0.729 \\
\hline AO fracture type C $n(\%)$ & & \\
\hline
\end{tabular}

Table 3 Complete list of comparative outcomes between the bridge plating and external fixation groups

\begin{tabular}{|c|c|c|c|c|}
\hline \multicolumn{4}{|c|}{ Continuous outcomes for bridge plate vs. external fixation } & \\
\hline Variables & $\begin{array}{l}\text { Bridge plate } \\
\text { mean }(95 \% \mathrm{Cl})\end{array}$ & $\begin{array}{l}\text { External fixation } \\
\text { mean }(95 \% \mathrm{Cl})\end{array}$ & $p$-Value & \\
\hline Radial height (mm) & $10.30(10.30-10.30)$ & $10.11(8.97-11.25)$ & 0.708 & \\
\hline Radial inclination (degrees) & $20.90(18.68-23.12)$ & $21.31(19.62-23.01)$ & 0.760 & \\
\hline Volar tilt (degrees) & $4.10(3.14-5.06)$ & $4.56(3.09-6.04)$ & 0.589 & \\
\hline Ulnar variance $(\mathrm{mm})$ & $0.72(0.08-1.37)$ & $1.24(0.73-1.75)$ & 0.202 & \\
\hline DASH score & $23.80(8.02-39.58)$ & $17.16(10.40-23.92)$ & 0.416 & \\
\hline \multicolumn{5}{|c|}{ Categorical outcomes for bridge plate vs. external fixation } \\
\hline Variables & $\begin{array}{l}\text { Bridge plate est. } \\
\text { rate }(95 \% \mathrm{Cl})\end{array}$ & $\begin{array}{l}\text { External fixation est. } \\
\text { rate }(95 \% \mathrm{Cl})\end{array}$ & Odds ratio & $p$-Value \\
\hline Infections & $2(1-10)$ & $10(7-14)$ & 0.21 & 0.050 \\
\hline latrogenic fracture & $0(0-0)$ & $0(0-1)$ & - & - \\
\hline Hardware failure & $4(1-10)$ & $1(0-2)$ & 5.22 & 0.026 \\
\hline Complex regional pain syndrome & $1(0-3)$ & $4(2-7)$ & 0.14 & 0.040 \\
\hline Nerve palsy and complications & $1(0-3)$ & $3(2-6)$ & 0.16 & 0.063 \\
\hline Scar complications & $1(0-8)$ & $2(1-3)$ & 0.77 & 0.810 \\
\hline Late carpal tunnel syndrome & $0(0-0)$ & $3(1-6)$ & - & - \\
\hline Loss of reduction & $0(0-0)$ & $2(1-5)$ & - & - \\
\hline Malunion or delayed union & $0(0-0)$ & $3(1-9)$ & - & - \\
\hline Arthritis & $0(0-0)$ & $0(0-3)$ & - & - \\
\hline Pseudoarthrosis & $0(0-0)$ & $0(0-1)$ & - & - \\
\hline Finger stiffness & $6(1-29)$ & $3(1-10)$ & 2.30 & 0.492 \\
\hline Shoulder capsulitis & $0(0-0)$ & $1(0-2)$ & - & - \\
\hline Unplanned reoperation & $4(1-10)$ & $3(2-6)$ & 1.11 & 0.880 \\
\hline Gartland and Werley: excellent/good & $91(91-91)$ & $83(72-90)$ & 2.09 & 0.016 \\
\hline
\end{tabular}

Abbreviations: $\mathrm{Cl}$, confidence interval; DASH, Disability of the Arm, Shoulder, and Wrist; est. estimated.

groups. The bridge plating group had a higher proportion of male patients. Furthermore, the bridge plating group had more dominant extremity injuries and AO fracture type B. However, while there are differences between the two groups, it is unclear if these differences would have a significant impact on clinical outcome.

\section{Conclusion}

Bridge plating appears to be a suitable alternative to ExFix for distal radius fractures. However, there are limited number of comparative studies to draw any definite conclusions in terms of clinical superiority and safety. Future directions 
would include prospective comparative studies between bridge plating and ExFix, evaluating for functional and radiographic outcomes.

Note

This study was conducted at Rothman Institute at Thomas Jefferson University, Philadelphia, PA.

Conflict of Interest

None declared.

\section{References}

1 Karl JW, Olson PR, Rosenwasser MP. The epidemiology of upper extremity fractures in the united states, 2009. J Orthop Trauma 2015;29(08):e242-e244

2 Chung KC, Spilson SV. The frequency and epidemiology of hand and forearm fractures in the United States. J Hand Surg Am 2001; 26(05):908-915

3 Larsen CF, Lauritsen J. Epidemiology of acute wrist trauma. Int J Epidemiol 1993;22(05):911-916

4 Slutsky DJ. External fixation of distal radius fractures. J Hand Surg Am 2007;32(10):1624-1637

5 Burke EF, Singer RM. Treatment of comminuted distal radius with the use of an internal distraction plate. Tech Hand Up Extrem Surg 1998;2(04):248-252

6 Hanel DP, Lu TS, Weil WM. Bridge plating of distal radius fractures: the Harborview method. Clin Orthop Relat Res 2006;445(445): 91-99

7 Ginn TA, Ruch DS, Yang CC, Hanel DP. Use of a distraction plate for distal radial fractures with metaphyseal and diaphyseal comminution. Surgical technique. J Bone Joint Surg Am 2006;88(Suppl. 1, Pt. 1):29-36

8 Richard MJ, Katolik LI, Hanel DP, Wartinbee DA, Ruch DS. Distraction plating for the treatment of highly comminuted distal radius fractures in elderly patients. J Hand Surg Am 2012;37(05):948-956

9 Ruch DS, Ginn TA, Yang CC, Smith BP, Rushing J, Hanel DP. Use of a distraction plate for distal radial fractures with metaphyseal and diaphyseal comminution.J Bone Joint Surg Am 2005;87(05):945-954

10 Tinsley BA, Ilyas AM. Distal radius fractures in a functional quadruped: spanning bridge plate fixation of the wrist. Hand Clin 2018;34(01):113-120

11 Hanel DP, Ruhlman SD, Katolik LI, Allan CH. Complications associated with distraction plate fixation of wrist fractures. Hand Clin 2010;26(02):237-243

12 Kumbaraci M, Kucuk L, Karapinar L, Kurt C, Coskunol E. Retrospective comparison of external fixation versus volar locking plate in the treatment of unstable intra-articular distal radius fractures. Eur J Orthop Surg Traumatol 2014;24(02):173-178

13 Williksen JH, Frihagen F, Hellund JC, Kvernmo HD, Husby T. Volar locking plates versus external fixation and adjuvant pin fixation in unstable distal radius fractures: a randomized, controlled study. J Hand Surg Am 2013;38(08):1469-1476

14 Grewal R, MacDermid JC, King GJ, Faber KJ. Open reduction internal fixation versus percutaneous pinning with external fixation of distal radius fractures: a prospective, randomized clinical trial. J Hand Surg Am 2011;36(12):1899-1906

15 Leung F, Tu YK, Chew WY, Chow SP. Comparison of external and percutaneous pin fixation with plate fixation for intra-articular distal radial fractures. A randomized study. J Bone Joint Surg Am 2008;90(01):16-22

16 Atroshi I, Brogren E, Larsson GU, Kloow J, Hofer M, Berggren AM. Wrist-bridging versus non-bridging external fixation for displaced distal radius fractures: a randomized assessor-blind clinical trial of 38 patients followed for 1 year. Acta Orthop 2006;77(03):445-453

17 Kreder HJ, Agel J, McKee MD, Schemitsch EH, Stephen D, Hanel DP. A randomized, controlled trial of distal radius fractures with metaphyseal displacement but without joint incongruity: closed reduction and casting versus closed reduction, spanning external fixation, and optional percutaneous K-wires. J Orthop Trauma 2006;20(02):115-121

18 Dodds SD, Save AV, Yacob A. Dorsal spanning plate fixation for distal radius fractures. Tech Hand Up Extrem Surg 2013;17(04): 192-198

19 Aktekin CN, Altay M, Gursoy Z, Aktekin LA, Ozturk AM, Tabak AY. Comparison between external fixation and cast treatment in the management of distal radius fractures in patients aged 65 years and older. J Hand Surg Am 2010;35(05):736-742

20 Wright TW, Horodyski M, Smith DW. Functional outcome of unstable distal radius fractures: ORIF with a volar fixed-angle tine plate versus external fixation. J Hand Surg Am 2005;30(02):289-299

21 Hegeman JH, Oskam J, Vierhout PA, Ten Duis HJ. External fixation for unstable intra-articular distal radial fractures in women older than 55 years. Acceptable functional end results in the majority of the patients despite significant secondary displacement. Injury 2005;36(02):339-344

22 Gartland JJ Jr, Werley CW. Evaluation of healed Colles' fractures. J Bone Joint Surg Am 1951;33-A(04):895-907

23 Hudak PL, Amadio PC, Bombardier C; The Upper Extremity Collaborative Group (UECG). Development of an upper extremity outcome measure: the DASH (disabilities of the arm, shoulder and hand) [corrected]. Am J Ind Med 1996;29(06):602-608

24 Kennedy CA, Beaton DE, Solway S, McConnell S, Bombardier C. The DASH Outcome Measure User's Manual. 3rd ed. Toronto: Institute for Work and Health; 2011 